\title{
Concurrent C: Safe Communities 13 HOW YOUTH DEVELOPMENT AND COMMUNITY COLLABORATION CONTRIBUTE TO SAFE COMMUNITIES
}

doi:10.1136/injuryprev-2012-040580d.13

R Davis*. The Wellington Boys' and Girls Institute, 3 MacDonald Cres, Wellington, New Zealand

Background The Wellington Boys' and Girls' Institute (BGI) is a youth development organisation that works in partnership with the Wellington City Council (WCC) to make Wellington a safer community for all its residents, particularly young people. Collaboration between BGI, the WCC and other community groups has had a range of positive outcomes that contribute to city safety.

Objective To explore the value of collaboration between youth development organisations, city authorities and other community groups in improving city safety.

Outcomes BGI and the WCC work closely together to develop responses to issues affecting young people and families in Wellington City, along with other partners including government agencies, churches, community groups, private businesses and the Police. This collaborative approach has led to the initiation of multiple innovative projects (such as mentoring, adventure therapy and graffiti vandalism prevention programmes) that have had a positive effect on city safety including reduction of crime, improved mental health and increased youth, family and community resilience. One of the key learning outcomes from this case study has been that collaboration between multiple partners and the synergy that is created through working together leads to increased opportunities and greater innovation in addressing issues of community safety.

Significance Government agencies and city authorities would benefit from working together with local community groups when seeking to address issues of community safety. 